\title{
Investigation of the Lean Stable Limit of a Barrier Discharge Igniter and of a Streamer-Type Corona Igniter at Different Engine Loads in a Single- Cylinder Research Engine ${ }^{\dagger}$
}

\author{
Federico Ricci 1,*, Luca Petrucci ${ }^{1}$, Valentino Cruccolini ${ }^{1}$, Gabriele Discepoli ${ }^{1}$, \\ Carlo N. Grimaldi ${ }^{1}$ and Stefano Papi $2, *$ \\ 1 Department of Engineering, Università degli Studi di Perugia, Via G. Duranti 93, 06125 Perugia, Italy; \\ luca.petrucci1@studenti.unipg.it (L.P.); valentino.cruccolini@unipg.it (V.C.); \\ gabriele.discepoli@unipg.it (G.D.); carlo.grimaldi@unipg.it (C.N.G.) \\ 2 Federal-Mogul Powertrain Italy, a Tenneco Group Company, Stabilimento Ignition-Carpi, \\ Via Della Scienza 6/8, 41012 Carpi (MO), Italy \\ * Correspondence: federico.ricci4@studenti.unipg.it (F.R.); Stefano.Papi@tenneco.com (S.P.) \\ † Presented at the First World Energies Forum, 14 September-5 October 2020; Available online: \\ https://wef.sciforum.net/.
}

Published: 11 September 2020

\begin{abstract}
Currently, the Radio-Frequency Corona Ignition systems represent an important solution for reducing pollutant emissions and fuel consumption related to Internal Combustion Engines, while at the same time ensuring high performance. These igniters are able to extend the lean stable limit by increasing the early flame growth speed. Kinetic, thermal, and ionic effects, together with the peculiar configuration of the devices, allow the combustion process to start in a wider region than the one involved with the traditional spark. In this work two corona igniters, namely a Barrier Discharge Igniter and a Corona Streamer Igniter, were tested in a single-cylinder research engine fueled with gasoline at different engine loads in order to investigate the igniters' performance through indicated analysis and pollutant emissions analysis. For each operating point, the devices' control parameters were set to ensure maximum energy releasement into the medium with the aim of investigating, at the extreme operating conditions, the capability of the devices to extend the lean stable limit of the engine. The corona igniters were tested on a constant volume calorimeter as well, reproducing the engine pressure conditions at the corresponding ignition timing. The target was to give an estimation of the thermal energy released during the discharge and then to compare their capability to provide high-stability energy.
\end{abstract}

Keywords: corona ignition; streamers; engine; combustion; emissions; calorimeter; thermal energy

\section{Introduction}

Nowadays, automotive research is focused on developing innovative solutions such as engine downsizing [1-3], cooled external exhaust gas recirculation (EGR) [4,5], water injection [6], and lean mixture operations $[7,8]$, to satisfy both the stringent regulations of pollutant emissions and customer requirements $[9,10]$.

Engines operating with the traditional spark-ignition (SI) system are currently unfit to guarantee high performance together with low emissions at lean and/or diluted operating conditions [11-15]. Many attempts have been made out to improve the conventional SI combustion process by varying the discharge interval $[16,17]$ or by improving the released thermal energy [18], but issues such as 
fouling, erosion, and heat loss through the electrodes have led automotive research to look for other solutions [19-21].

Low-temperature plasma (LTP)-based ignition systems represent an innovative concept able to overcome the abovementioned limits and to extend the engine stable operating conditions [22,23] by promoting an early flame development at lean and/or diluted conditions [24-26]. Besides the thermal effect typical of the traditional spark [27], these systems reduce the mixture ignition delay and enhance the combustion process by means of kinetic and transport effects $[28,29]$. Kinetic effects are related to the production radical and excited species, mainly atomic oxygen, able to reduce the reaction time of fuel oxidation [30], whereas the transport effects are connected to the collisions between neutral gas molecules and discharged-particles [31].

One of the most interesting LTP solutions is represented by the Advanced Corona Ignition Systems (ACIS) [32,33], to whose family belong the corona streamer-type igniter (CSI) $[34,35]$ and the barrier discharge igniter (BDI) [36,37]. Generally speaking, the corona-effect is based on the production of ionization waves, namely streamers, produced by a high-frequency electric field once exceeding the activation threshold [38,39].

In the CSI configuration, the streamers spread out from a star-shaped electrode, generally with four or five tips, towards the grounded engine-walls and the piston head. In this way a wider mixture volume with respect to a spark plug is involved, therefore leading to the generation of simultaneous and multiple ignition points $[40,41]$. However, low-temperature plasma benefits can be lost at lowpressure and at high-voltage, once spark-like events occur due to the streamer-to-spark transition, i.e., the impingement of the ionization waves on the engine walls [42,43] and the subsequent generation of a stable conductive path. An extensive management of the control parameters is hence required in order to avoid this undesirable condition [44,45].

Differently to the previous model, the BDI design avoids the arc-condition by means of a breakdown protection system. The streamers, generated by an annular plug shell, propagate on a hemispheric dielectric surface which covers the high-voltage electrode, and release charge on it, inhibiting the spreading of subsequent waves in the same spatial location [46]. In this way, plasma benefits are maintained, while at the same time releasing high thermal energy thanks to the possibility to operate with higher voltage levels also at low pressure [34,45]. Therefore, the control strategy is simplified and the operating range is extended to regions otherwise inaccessible with other LTP igniters. Moreover, the insulator surface shields the igniter-core from electrical erosion [32,22] and chemical exposition of the active species produced during the discharge [47,48].

The ACISs are designed to operate with a Radio-Frequency (RF) input voltage, belonging to the $0.7-5.0 \mathrm{MHz}$ range. Among these, the most interesting solution is represented by the corona igniters powered with an input voltage of about $1.04 \mathrm{MHz}[32-35,41,44]$. These devices have been recently investigated by the research community at real engine operating conditions.

The capability of the RF-CSI to extend the lean stable limit $[35,41,49]$, to reduce pollutant emissions [44,50], and to improve the EGR tolerance $[26,39,51]$ with respect to traditional spark have been demonstrated.

Concerning the BDI, besides the enhancement of the combustion performance recently showed by Siraishi and Urushihara [22], Idicheria also demonstrated an improvement of the dilution tolerance and knock tolerance in comparison with traditional spark. Furthermore, in the same work, the interesting possibility to modulate the discharge to produce pre-strikes before the fuel injection on a gasoline direct injection (GDI) engine was investigated [46]. The generation of active radical species and ozone results in promoting and enhancing the combustion process [52-54]. In comparison with the corona-streamer type, the behavior of the barrier discharge igniter has not yet been deeply investigated by the research community.

Within this contest, a comparison between a barrier discharge igniter and a corona-streamer type is performed in this work by determining the differences in terms of control, combustion behavior, and capability to extend the lean stable limit of the engine. The potentiality of these two igniters is investigated by managing two setting-parameters, which makes it possible to control the device 
activation time (corona duration) and the electric field intensity at the firing-end (supply voltage) $[44,55,56]$.

The BDI is tested at the maximum allowable setting values, whereas the CSI needs a reduction of the supply voltage, depending on the operating conditions, in order to prevent unwanted sparklike events.

First, experimental tests are carried out in a single-cylinder research engine at $1000 \mathrm{rpm}$ and medium load (IMEP $=5.9$ bar @ $\lambda=1$ ). This campaign represents an extension of the activity previously performed by our research group at low load (IMEP $=4.5$ bar @ $\lambda=1$ ) [56]. The aim of this work is to investigate the igniters' behavior at operating conditions not yet explored by the group, comparing the corresponding results with the ones obtained at low load, through the indicated analysis. On both test campaigns exhaust gas analysis is carried out as well.

In the second part of the work, the igniters are tested in a pressure-based calorimeter, using air as medium and reproducing the engine pressure conditions, with the aim of estimating the thermal energy released by the corona discharges $[34,45]$. In fact, the chemical activities cannot be separated from the thermal aspect, which contributes to the fuel oxidation [57-59]. For this reason, the characterization of this latter effect can be helpful to better understand behavior and performance of the devices.

Furthermore, the outputs of this work can be used as validation data for the 3D-CFD simulations where no models are yet available to correctly describe at the same time the released thermal energy and the number of radicals generated by the kinetic effect $[55,60]$.

\section{Materials and Methods}

\subsection{Single-Cylinder Engine}

Measurements were carried out on a 500-cc single-cylinder engine (Figure 1a) with four valves, pent-roof combustion chamber, and a reverse tumble intake port system which is designed to operate in Direct Injection (DI) or Port Fuel Injection (PFI) (Table 1). The tests were conducted in PFI mode with the igniters (BDI or CSI) centrally located (Figure 1b). The engine can be also configurated to allow optical access, however, in this work the quartz piston crown was replaced by a metal one (Figure 1c) in order to safeguard the optical configuration from the higher operating pressures characterizing the medium load.

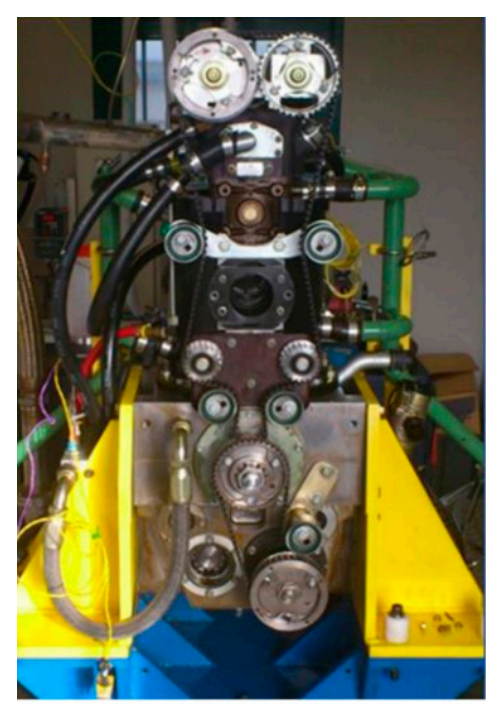

(a)

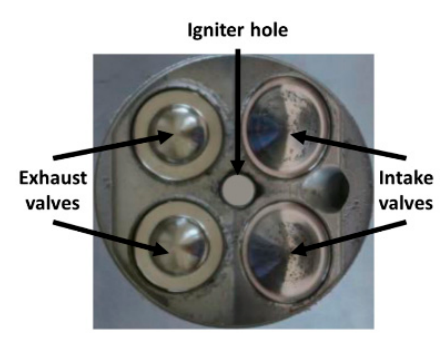

(b)

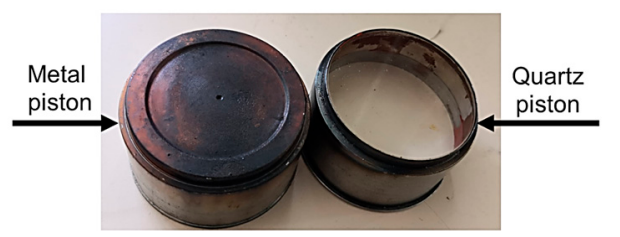

(c)

Figure 1. (a) Test engine, (b) details of engine head, (c) metal piston (left) and quartz one (right). 
All mechanical moving parts were lubricated by conventional mineral oil at the temperature of $343.0 \pm 0.2 \mathrm{~K}$, the same as the coolant one. This value made it possible to lengthen the engine durability, while reducing blow-by at the same time. An AVL 5700 dynamic brake ensured the engine speed control both in motored and firing condition. The air-fuel ratio $(\lambda)$ was set by reducing or increasing the fueling with fixed throttle position, in order to maintain the same turbulence level inside the combustion chamber. Standard European market gasoline (E5, with RON $=95$ and MON $=85$ ) was injected at a fixed absolute pressure of 5 bar by means of a port fuel injector (Weber IWP092).

Table 1. Engine data.

\begin{tabular}{ccc}
\hline Feature & Value & Unit \\
\hline Displaced volume & 500 & $\mathrm{cc}$ \\
\hline Stroke & 88 & $\mathrm{~mm}$ \\
\hline Bore & 85 & $\mathrm{~mm}$ \\
\hline Connecting rod length & 139 & $\mathrm{~mm}$ \\
\hline Compression ratio & $8: 8: 1$ & - \\
\hline Number of valves & 4 & - \\
\hline Exhaust valve open & 13 & CAD bBDC \\
\hline Exhaust valve close & 25 & CAD aBDC \\
\hline Intake valve open & 20 & CAD bBDC \\
\hline Intake valve close & 24 & CAD aBDC \\
\hline
\end{tabular}

A research ECU (Athena GET HPUH4) controlled the energizing time of the injector and the ignition timing by sending a trigger signals to the igniter control unit. A piezoresistive transducer (Kistler 4075A5) on the intake measured the intake port pressure and a piezoelectric transducer (Kistler $6061 \mathrm{~B}$ ) on the side of the chamber measured the in-cylinder pressure. A Kistler Kibox (Figure 2) combustion analysis system (temporal resolution of $0.1 \mathrm{CAD}$ ) acquired the pressure signals, the absolute crank angular position measured by an optical encoder (AVL 365C), the $\lambda$ measured by a fast lambda probe at the exhaust (Horiba MEXA- 720, accuracy of $\pm 2.5 \%$ ), the ignition signal from ECU, and the trigger signal used for synchronization purposes. A total of 80 consecutive combustion events were recorded for each operating point tested. The exhaust gas analysis was performed by a Horiba MEXA 7100D with an OVN 723-A.

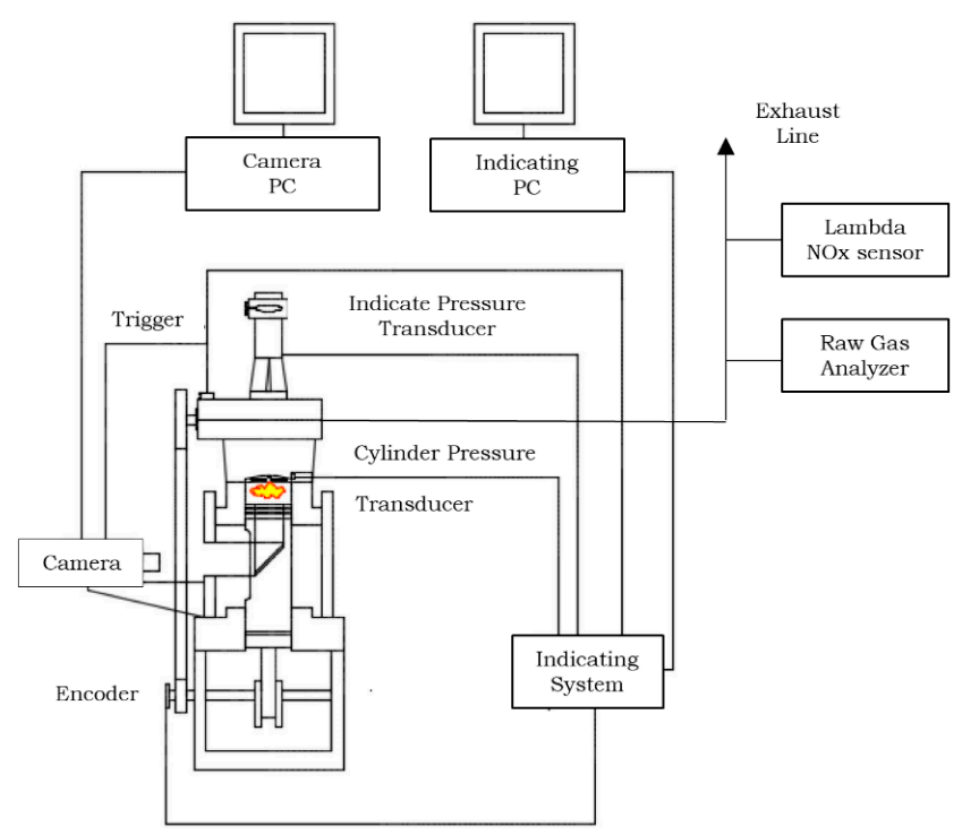

Figure 2. Engine experimental apparatus. 


\subsection{Pressure-Based Calorimeter}

The corona devices were tested on a plexiglass constant volume vessel $\left(\mathrm{V}_{c}=22.5 \mathrm{~cm}^{3}\right)$ able to ensure low thermal conductibility $\left(0.187 \mathrm{Wm}^{-1} \mathrm{~K}^{-1}\right)$, using air as medium at steady-state conditions, without charge motions. Concerning the experimental apparatus, each discharge event was triggered by means of a TTL signal produced by an arbitrary wave generator (HP 33120A) and the current supply to the igniter coil was recorded by a current probe (Teledyne LeCroy CP030, accuracy $\pm 1.5 \%$ full scale). A piezoelectric pressure transducer (Kistler Type 7261, $2200 \mathrm{pC} \cdot$ bar $^{-1}$ of sensitivity and $\approx 10^{-5}$ bar of resolution) recorded the pressure fluctuations inside the chamber due to the discharge events and an Amplifier (Kistler Type 5011) converted the charge transmitted by the pressure sensor into a proportional voltage signal. All of the quantities were acquired by a fast oscilloscope (Teledyne LeCroy Wavesurfer 3000) with a sampling frequency of $10 \mathrm{MHz}$, about ten-times bigger than the frequency of the current (Figure 3).

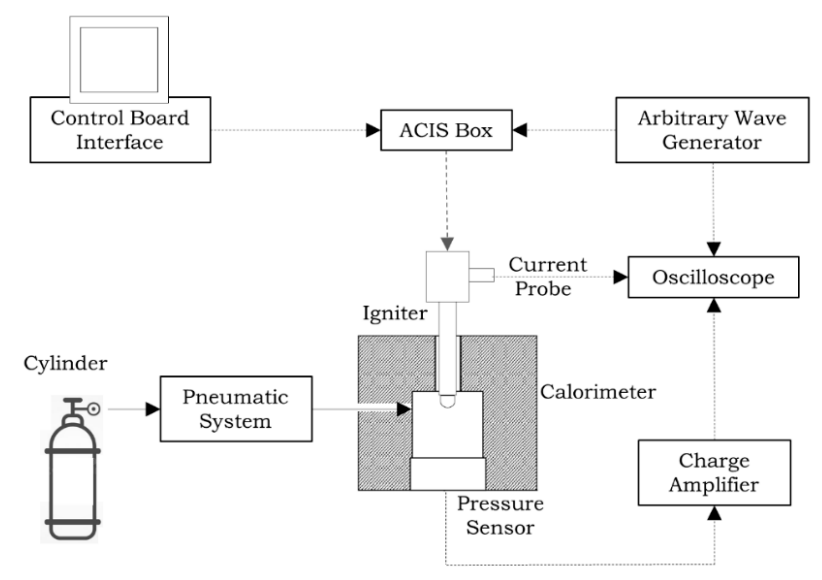

Figure 3. Calorimeter experimental apparatus.

Upon filtering the pressure signal and computing the estimated pressure variation $(\Delta \mathrm{P})$ due to the discharge (Figure 4), the thermal energy released (ER) in the inert environment was calculated by assuming the adiabaticity of the chamber and by applying the first law of thermodynamics, obtaining (1):

$$
E_{R}=\frac{1}{\gamma-1} V_{c} \Delta P
$$

where $\gamma$ is the specific heat ratio of the gas.

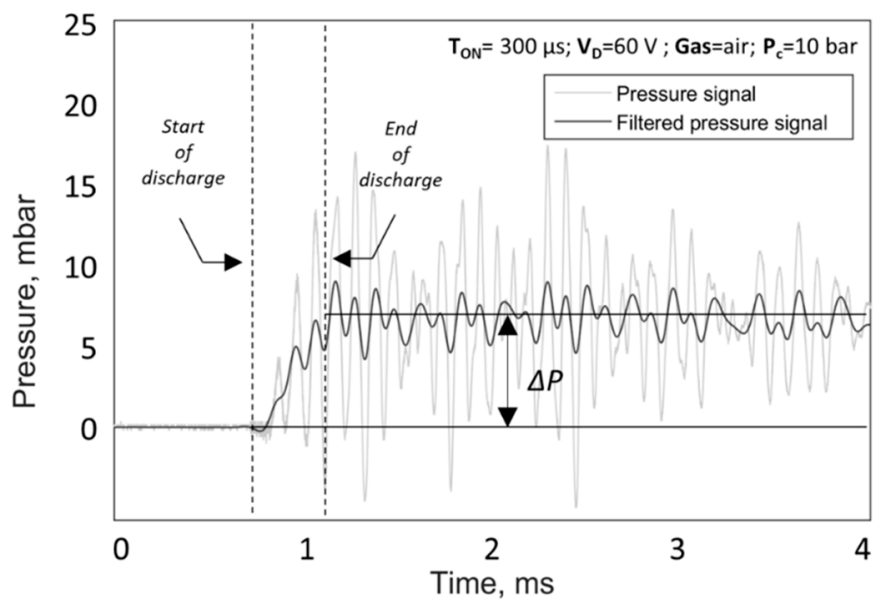

Figure 4. Example of the recorded pressure signal (grey signal) due to the igniter discharge and corresponding filtered signal (black line). The superior mean value of this latter was used to estimate the pressure variation due to the discharge. 
In conclusion, the energy released by the device, at the specific tested point, was defined as the mean value of 50 consecutive shots $\left(\overline{\mathrm{E}_{\mathrm{R}}}\right)$. This number of events made it possible to obtain valuable statistical data, by avoiding at the same time a change in the discharge behavior due to excessive gas conditioning.

\subsection{Igniters}

The Radio-Frequency advanced corona igniters, chosen in this work to develop the experimental campaign, were provided by Federal Mogul Powertrain, a Tenneco group company. Both devices are controlled by the same electronic system, which powers the igniters assembly, upon receiving the trigger signal from the engine control unit (ECU), in the engine-setup, or from an arbitrary wave generator (HP 33120A), in the calorimeter-setup. The input frequency is $1.04 \mathrm{MHz}$ and corresponds to the resonance frequency of the equivalent RLC circuit (Figure 5) [34,41]. The igniter assembly is composed of an inductor and a firing end, linked through an extension. The inductor increases the input voltage to the desired value and the firing-end starts the corona-effect by means of the generation of a strong electric field.
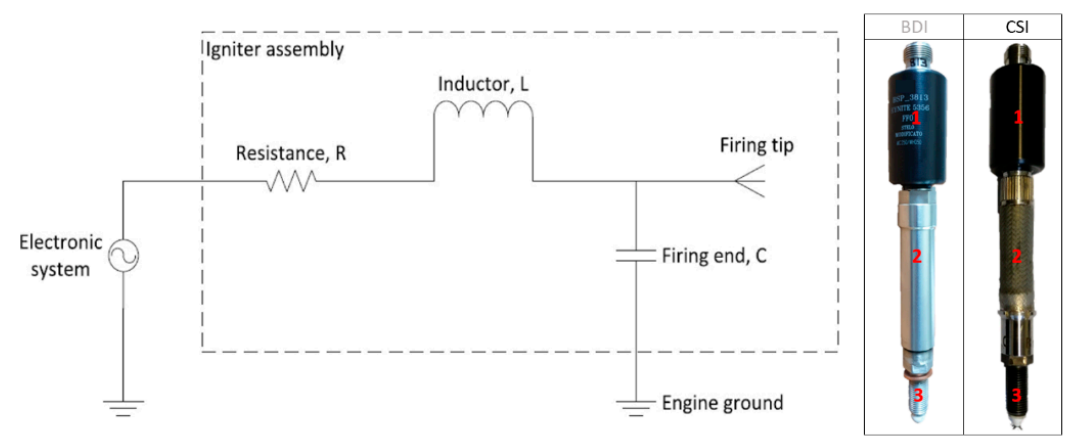

Figure 5. Equivalent RLC circuit of the tested igniters $(1=$ inductor, $2=$ connection, $3=$ firing end $)$.

The corona behavior is controlled by two setting parameters: the supply voltage $\left(V_{D}\right)$ and the corona duration (Ton).

The first one, proportional to the electrode voltage [34,56], is responsible for the corona development, whose penetration into the medium depends on the working conditions. The corona duration represents the activation time of the igniters and plays an important role in reducing the cycle-to-cycle variability [26].

Starting from the four-tip electrode (Figure 6a), the CSI streamers propagate into the medium towards the counter-electrode represented by chamber walls in the engine $[35,41,44]$ or by the pressure sensor membrane in the pressure vessel [34,45,55]. BDI streamers start from the zeropotential thread and propagates around the hemispherical insulator, which completely surrounds the high-voltage electrode [33] (Figure 6b).

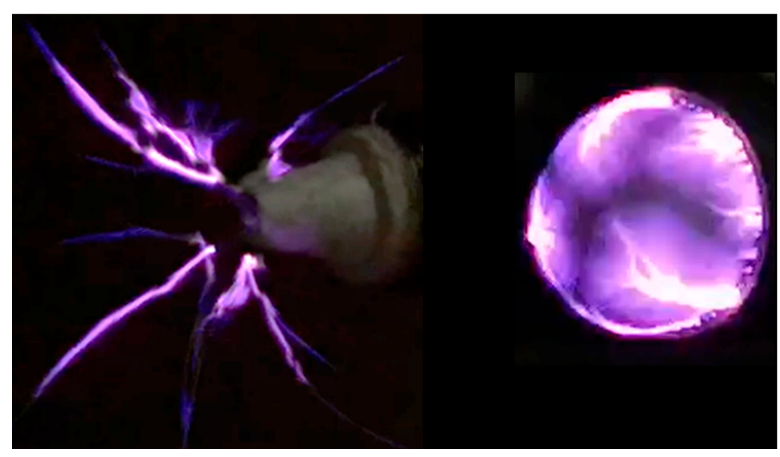

(a)

(b)

Figure 6. Representation of the streamers development produced by a corona-streamer discharge (a) and a barrier discharge $(\mathbf{b})$. 


\section{Experimental Campaign}

\subsection{Single-Cylinder Engine}

The target of this work was to compare the lean stable limit of two corona igniters at low enginespeed and at two different load conditions, comparing the corresponding results. The work was based on an exploration of the igniters' behavior on a conventional PFI engine, without charge conditioning and/or prestrikes. All tests were carried out achieving the maximum brake torque (MBT), which was found to occur in the tested points when the combustion center (MFB50) was at around 9 CAD aTDC. It is possible to simultaneously manage the ignition timing (IT) and the control parameters (VD e Ton) (Figure 7).

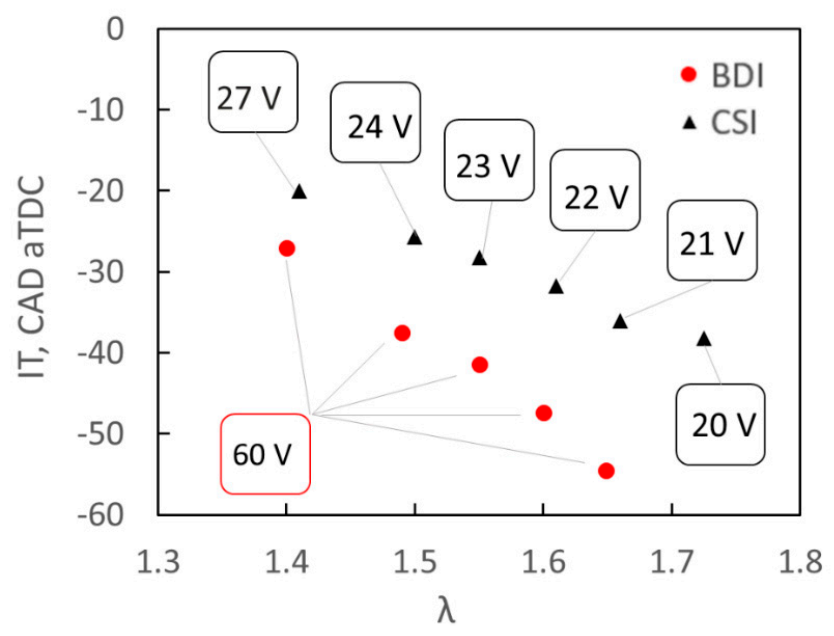

Figure 7. Ignition timing and corresponding driving voltage (red box for BDI and black box for CSI) of the corona igniters chosen to carry out the experimental campaign.

For both devices, the maximum allowable Ton $(1500 \mu \mathrm{s})$ to prevent coil overheating issues was chosen. BDI is able to avoid streamer-to-spark transition, therefore the maximum $V_{D}$ value allowed by the providers was chosen $(60 \mathrm{~V})$. After that, the IT was set to reach the MBT.

Instead, for the CSI a co-optimization between the $V_{D}$ and the IT was needed to maintain the frequency of arc-events below $1 \%$. The driving voltage value had to be changed according to the IT, because this latter value determines the operating pressure conditions and, consequently, the breakdown condition, at the ignition instant.

The ACIS ECU features an arc-detection algorithm that counts and stores the number of arc events. Therefore, upon setting the IT, if the $1 \%$ threshold was exceeded, the test point was discarded and then repeated with lower $V_{D}$. As already found in our previous work [56], the optimal IT of the CSI is closer to the TDC than the BDI one because of the faster flame development showed off in the first part of the combustion by the corona-streamer type. Tests were performed at $1000 \mathrm{rpm}$ at medium load (from now on ML), starting from the results obtained in low-load (from now on LL) [56]. In this latter case, the lean stable limit was found to be $\lambda=1.6$ for the CSI and $\lambda=1.55$ for the BDI; both higher than the one obtained with a conventional spark $(\lambda=1.4)$ [41]. Starting from this air/fuel value, a comparison between the results obtained at different operating loads was carried out. For all operating tested points, the air-fuel ratio was changed by fixing the throttle position in order to maintain the same turbulence level inside the chamber. Therefore, the $\lambda$ was controlled by varying the fuel injected quantity.

\subsection{Pressure-Based Calorimeter}

In the second part of the work the corona igniters were tested on the pressure-based calorimeter at an operating condition as close as possible to the engine one in order to give an estimation of the thermal energy released by the devices. 
According to the considerations of Section 2.2, lean mixture (more similar to air) and low-load (low turbulent motions) engine operating conditions were chosen in order to carry out the corresponding energy tests into the calorimeter, in particular the operating point @ $\lambda=1.5$ (Table 2).

Table 2. Calorimeter operating conditions, corresponding to the engine test at $\lambda=1.5$ at low load.

\begin{tabular}{ccc}
\hline & BDI & CSI \\
\hline Pressure interval (from-to), bar & $3.4-4.5$ & $5.6-7.2$ \\
Corona duration, $\mu$ s & 1500 & 1500 \\
Driving voltage, $V$ & 60 & 22 \\
Gas type & \multicolumn{2}{c}{ Air } \\
\hline
\end{tabular}

Considering that Ton $=1500 \mu \mathrm{s}$ at $1000 \mathrm{rpm}$ corresponds to $9 \mathrm{CAD}$, the in-cylinder pressure conditions considerably change during the test. For this reason, the mean in-cylinder pressure signal ( $\left.\mathrm{P}_{\mathrm{cyl}}\right)$ was divided into 15 intervals (corresponding to an activation time of $100 \mu \mathrm{s}$ ), in which the pressure can be considered "almost-constant" (Figure 8), to be then reproducible in the calorimeter.

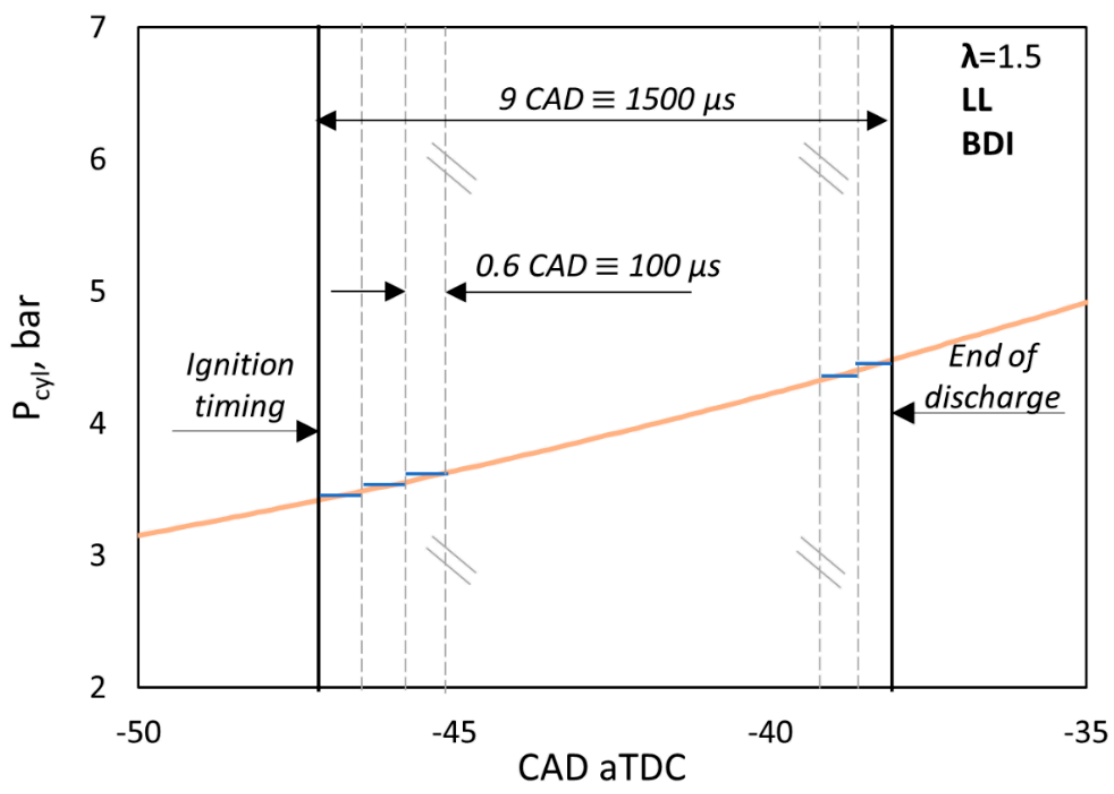

Figure 8. Example: the mean in-cylinder pressure (orange line) of 80 consecutive combustion events. The discharge duration was divided into same length intervals in order to test the corresponding pressure on the pressure based-calorimeter. Same considerations can be extended to the CSI, according to the parameters reported in Table 2.

\section{Results and Discussion}

\subsection{Single-Cylinder Engine}

As reported in Section 2.4, preliminary tests were carried out in order to establish, at each operating point tested, the optimal combination of $V_{D}$ and IT of the CSI able to avoid the arc-condition and to achieve the MBT. Figure 9 reports the Pcyl traces, in motored condition (solid lines), of both load cases analyzed, and the adopted combinations for both igniters. In general, the $P_{\text {cyl }}$ increased with the mass of air trapped inside the cylinder, turning out to be about 4 bars higher for the ML case compared to the LL case, at the TDC. Corona effect depends on the gas pressure, mixture quality, and charge turbulence $[34,35,41]$. Moving towards leaner conditions the IT has to be advanced due to the combustion duration increment and, consequently, the $V_{D}$ has to be lowered because of $P_{c y l}$ decrement, at specific low-load. Considering the same $\lambda$, the ML case required lower IT compared to the LL case. For example, at $\lambda=1.5$, the IT of the LL case was about 10 CAD advanced compared to 
the one of the ML case. In the latter case, a higher $V_{D}$ was available due to the higher Pcyl level. Moreover, the turbulence level also seems to play an important role in the development of the corona effect. In fact, taking into account a $V_{D}=22 \mathrm{~V}$, together with optimized IT, the ML case allows the ignition of leaner mixtures $(\lambda=1.6)$ compared to the LL case $(\lambda=1.5)$, even with higher $P_{\text {cyl. So, the }}$ ITs at ML are closer to the TDC, for both igniters.

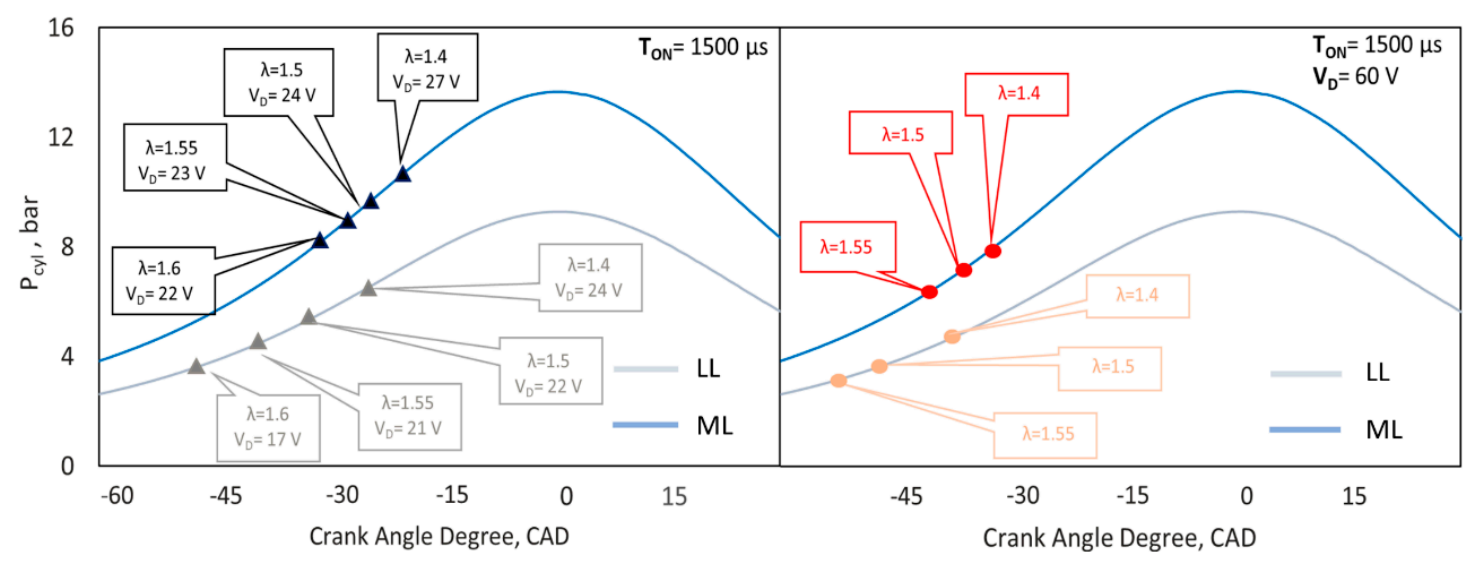

(a)

(b)

Figure 9. Control parameters (at motored condition) at each operating point tested for both igniters: (a) CSI case (triangles) and (b) BDI case (circles). Solid lines represent the Pcyl (CAD) at motored conditions and the overlapped markers indicate, at different $\lambda$, the driving voltage for CSI values.

At ML, BDI and CSI faced a further extension of the lean stable limit with respect to the one obtained in LL. The overall combustion stability is indicated by the coefficient of variation of IMEP ( $C$ oVImer). Each operating point was considered stable if $\mathrm{CoV}_{\text {IMEP }}<4 \%$. In the LL case, as already described, the lean limit was found to be $\lambda=1.55$ for the BDI and $\lambda=1.60$ for the CSI (Figure 10 top), both higher than the one featured by a conventional spark plug. At ML, the BDI kept the engine stable up to $\lambda=1.647$, whereas the CSI up to $\lambda=1.725$ (Figure 10 bottom). Therefore, wider throttle opening led to an extension of the lean stable limit of about $0.1 \lambda$ unit for both igniters compared to the LL case. According to these results, leaner mixtures can be elaborated in the ML case by providing the same power to the igniter coil, probably thanks to the higher turbulence levels of the charge, which promote the corona development inside the chamber. As expected, the ML case was characterized, at the same $\lambda$, by higher IMEP values caused by higher amount of air and gasoline introduced inside the chamber. In both load cases, no appreciable differences in terms of IMEP were found between the two igniters, thanks to the IT optimization.

Figure 11 shows the combustion steps referred to the average cycle, at the two load cases analyzed. The combustion events were divided into three intervals, from IT to MFB $=90 \%$. For both load cases, CSI performed a faster combustion in the first part (CA0-5, angular interval from IT to $\mathrm{MFB}=5 \%$. 


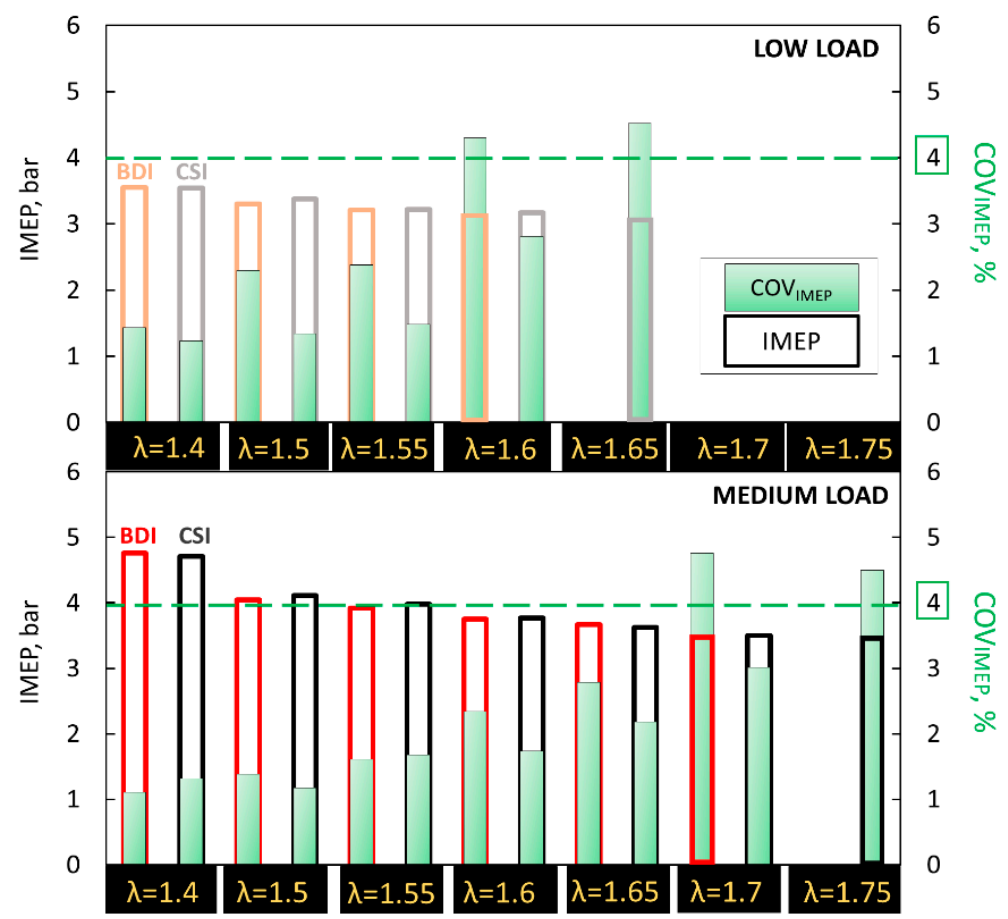

Figure 10. IMEP (empty bars) and CoVIMEP (colored bars inside the empty ones) at low load (upper) and medium load (bottom). The vertical left axis indicates the IMEP value whereas the right one the corresponding $\mathrm{CoV}$.

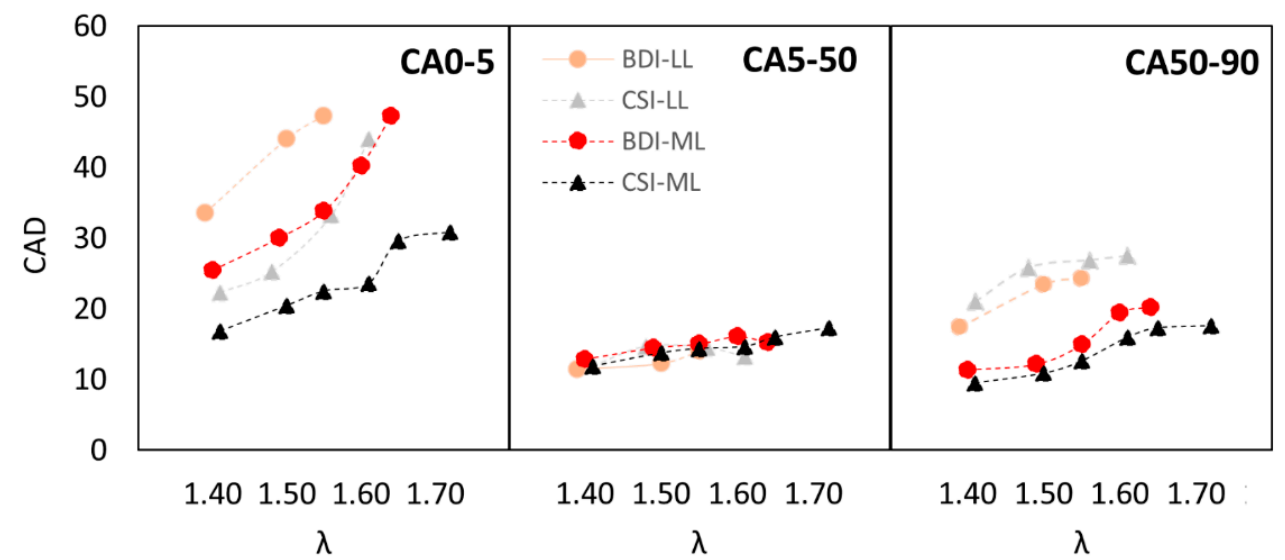

(a)

(b)

(c)

Figure 11. CA0-5 (a), CA5-50 (b), and CA50-90 (c).

At ML, both igniters show reduced CA0-5 in comparison with LL one. BDI exhibited similar growth rate of the CA0-5 at both loads, whereas the turbulence motions seem to promote the coronastreamers' development. In fact, CA0-5 growth of the CSI was reduced by increasing the throttle valve opening.

At the same $\lambda$ condition, the duration of the second part of the combustion (CA5-50) was about the same for both igniters, while important differences were found in the third interval of the combustion (CA50-90). At LL, the BDI was able to guarantee a faster third part. On the contrary, the final combustion duration was reduced for the CSI at ML. In order to better analyze the igniters' behavior, Figure 12 reports the average combustion duration of the 80 consecutive cycles recorded at $\lambda=1.5$. As already seen, the BDI ignition timing was advanced due to the time required to center the half of the combustion around 9 CAD aTDC. In general, the turbulence motions ensure a reduction of the combustion duration, especially for the CSI. In fact, both igniters performed a faster CA0-50 at ML in comparison with LL case but, differently to what happened at low-load, CSI was able to complete the process more quickly with respect to BDI. Moreover, differently to the LL case, in which 
similar durations of the whole combustion process led to a comparable extension of the lean stable limit, in the ML case the CSI's capability to guarantee an extension much more remarkable in comparison with BDI was already evident at $\lambda=1.5$, thanks to an higher reduction of the combustion process duration with respect to the LL case.

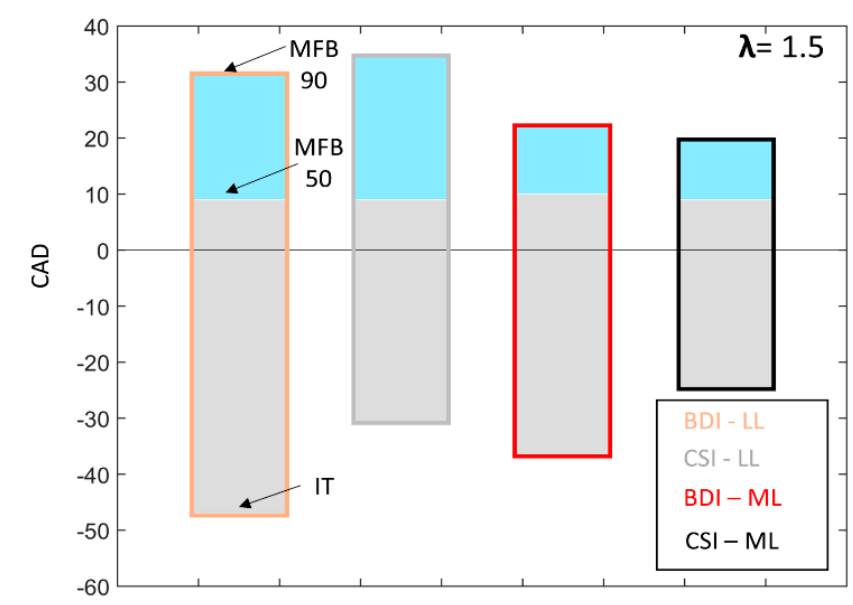

Figure 12. MFB50, MFB90, and corresponding CADs at $\lambda=1.5$.

These kinds of observations can be extended to the other $\lambda$ values and linked to the exhaust gas analysis (Figure 13).

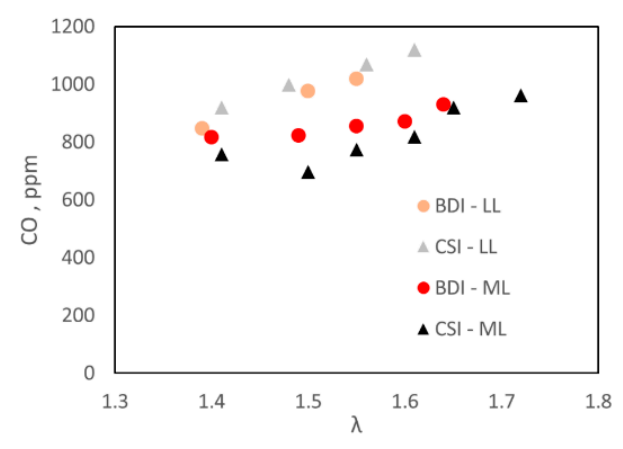

(a)

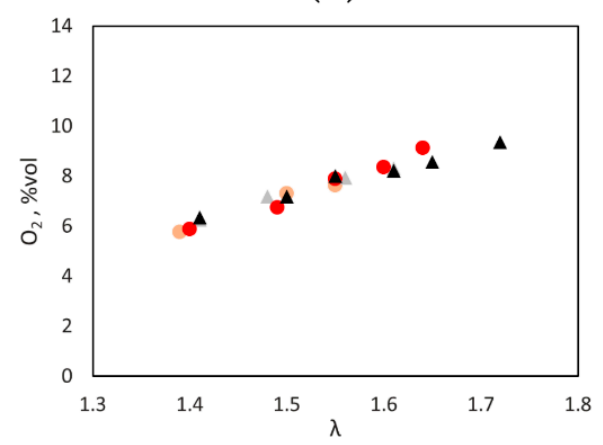

(c)

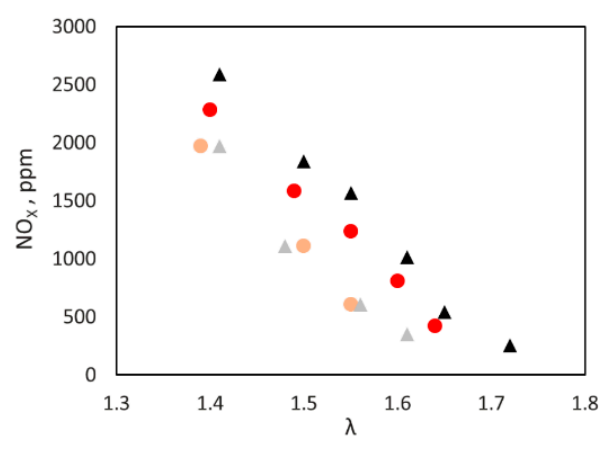

(b)

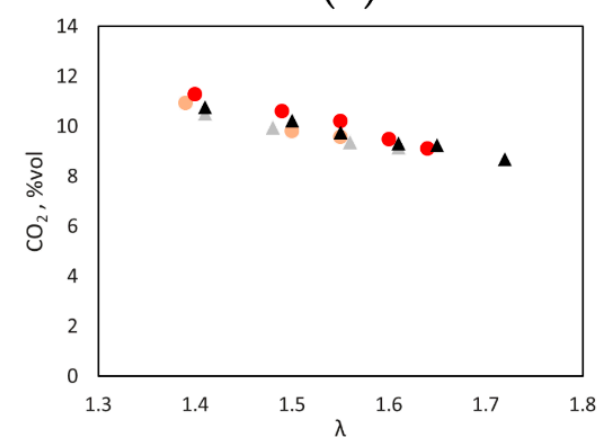

(d)

Figure 13. Raw pollutant emissions. (a) $\mathrm{CO},(\mathbf{b}) \mathrm{NO}_{x},(\mathbf{c}) \mathrm{O}_{2}$, and (d) $\mathrm{CO}_{2}$.

Concerning the carbon monoxide (CO), in both load cases, the global trend increased as $\lambda$ increased due to reduced fuel availability, as already found in [56]. At all ranges analyzed, the lower $\mathrm{CO}$ values at ML could be correlated to higher turbulence motions which enhance the mixing by promoting the fuel oxidation. The black line in Figure 14a fits the global distribution in order to highlight $\mathrm{CO}$ trend as a function of $\lambda$ and of the load operating conditions. It is worth mentioning that, if combustion is completed earlier during the expansion stroke, $\mathrm{CO}$ oxidation reaches a higher 
level of completion before oxidation freezing [61]. At LL the capability of BDI to complete the main combustion phase in a shorter time, compared to CSI one, led to lower CO emissions at all operating ranges.

At ML, BDI showed longer duration of CA50-90 and corresponding higher CO with respect to CSI. On the contrary, the CSI was able to complete the main combustion more quickly, so as to lower the CO levels.

Concerning the nitrogen oxides (NOx), in both load cases the maximum value was recorded, in this work, using weakly lean mixtures $(\lambda=1.4)$; the global trend decreases as $\lambda$ increases [62]. The higher values recorded at ML for both igniters can be related to higher temperatures, induced by higher operating pressure levels, with respect to the LL ones. Figure 14b highlights this kind of dependence through the NOx emissions plotted against the IMEP value, at all operating conditions analyzed. In the LL case, no particular differences were found between the corona igniters in terms of NOx emissions. At the same $\lambda$, the similarity was justified by the same global combustion durations shown by the igniters. At ML, the short combustion duration performed by the CSI probably led to high temperature and, consequently, higher levels of NOx compared to the BDI ones.

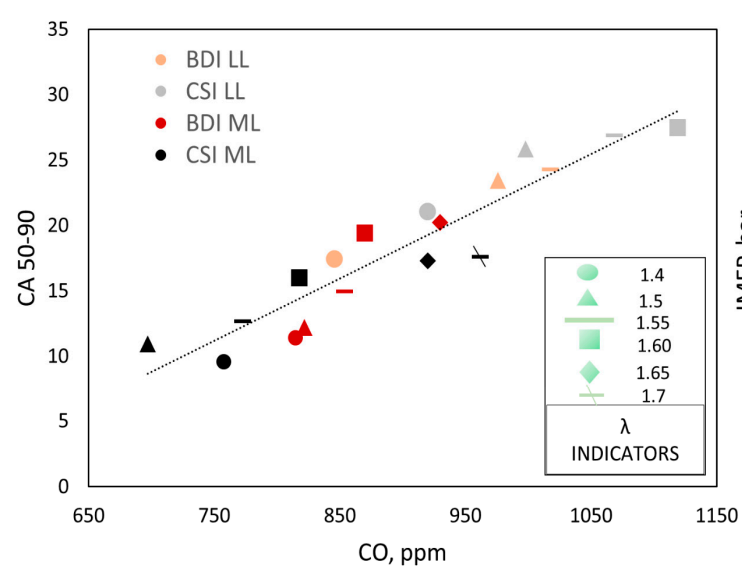

(a)

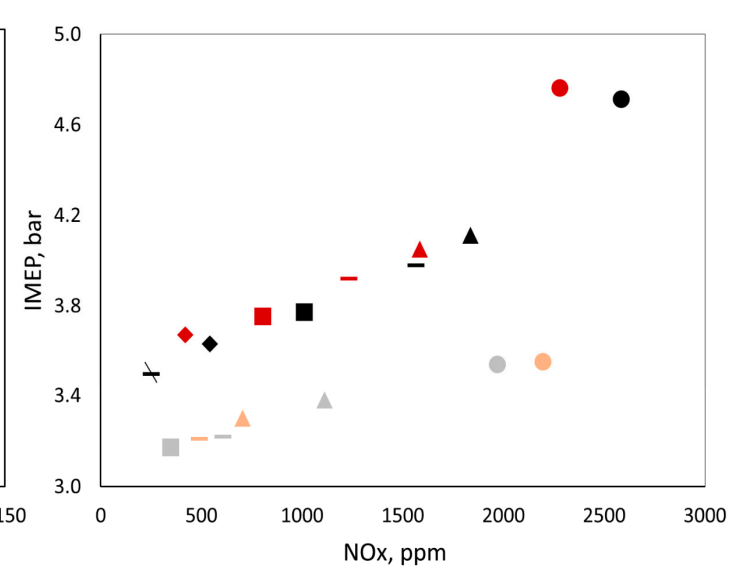

(b)

Figure 14. Representation of the relationship between (a) CO-CA50-90 and (b) NOx-IMEP, for all cases analyzed.

In conclusion, about the same levels of carbon dioxide $\left(\mathrm{CO}_{2}\right)$ and oxygen $\left(\mathrm{O}_{2}\right)$ were found for the different load cases analyzed, which only depend on the $\lambda$. At the same throttle valve opening and air/fuel ratio, the same gasoline quantity was introduced, therefore, no differences were found.

\subsection{Pressure-Based Calorimeter}

The aim of this paragraph is to better analyze the behavior of the corona devices and their capability to extend the lean stable limit by correlating many of previous results with the characterization of the thermal energy released by the discharges. Other considerations have been made in order to try to explain the differences which characterize the two ACISs tested in this work.

According to the considerations of Section 3.2, both igniters were tested in the constant-volume vessel at the operating conditions of Table 2. Figure 15 shows the obtained results according to the method of Section 3.2. The whole energy (Etot) was obtained as the sum of the 15 consecutive energy values, which are indicated through circles (BDI case) or triangles (CSI case).

While the thermal energy released by the barrier discharge igniter is substantially independent of the pressure, the CSI showed decreasing performance as the pressure increased. Higher energy of CSI can be related to the production of stronger electric fields amplified through the tips $[34,63]$. On the other side, the barrier discharge igniter is a streamer discharge in which the current is restricted by charging the dielectric layer [29]. Therefore, even if it is reasonable to expect lower thermal energy released, BDI is dedicated to the production of high amount of chemical species, especially ozone, by involving considerable volume mixture around its firing-end [63]. 


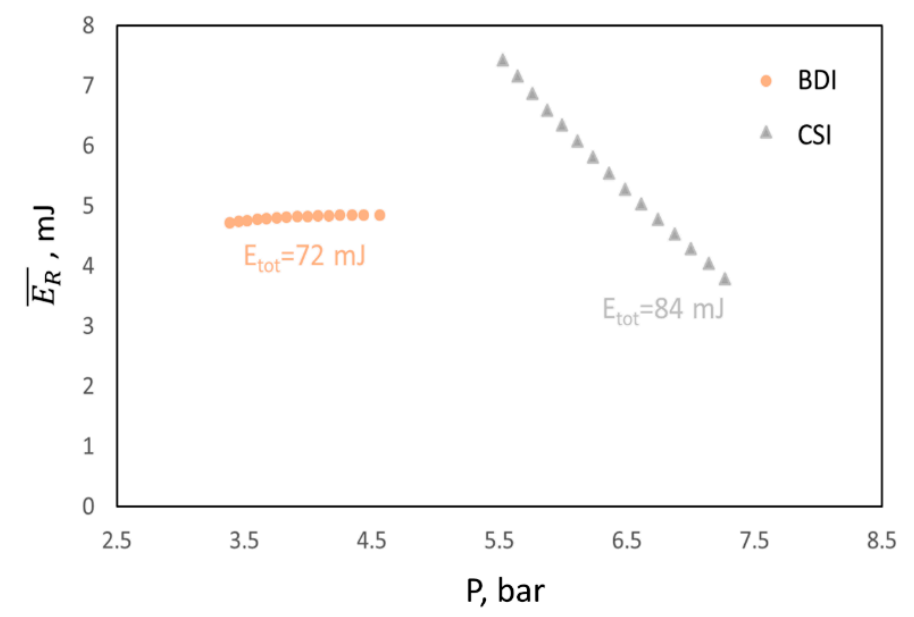

Figure 15. Whole thermal energy released by the corona igniters.

The extra radicals contributed by $\mathrm{O}_{3}$ molecules initiate and accelerate the chain-branching reactions and consequently increase the burning velocity. Ozone is a long-lasting species $[63,64]$ characterized by a formation time much longer than the oxygen atoms [65]. This concept could explain the advanced IT required by the BDI to develop the flame and its faster combustion after the MF50 at LL (Figure 12), which could be related to the 'delayed' beneficial action of $\mathrm{O}_{3}$ on enhancing the flame development.

However, BDI was able to perform a good extension of the lean limit also thanks to similar thermal energy levels compared to CSI. The faster flame development performed by this latter igniter could be related to the nature of the ignition in addition to the higher thermal energy which allows the development, in reduced time, of four well-defined kernels. In order to better understand the process, Figure 16 shows the flame development of the corona igniters recorded in the same engine at low-load [56]. The imaging analysis was developed in our previous work with the engine configured to allow optical access. It is possible to observe that the CSI is characterized by four welldefined kernels, whereas the BDI features a quasi-spherical shape. At the end of discharge (9 CADaIT), the CSI has already started the combustion and the flame is evident and highly developed, while BDI requires more time.

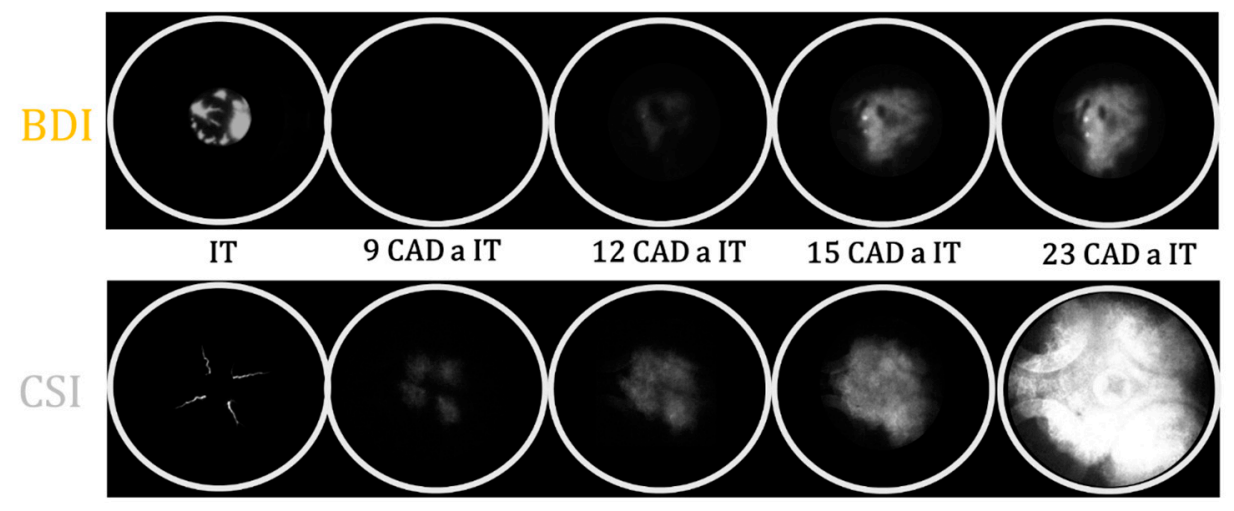

Figure 16. Combustion evolution for BDI and CSI, $\lambda=1.5$, low-load condition.

\section{Conclusions}

In this work a characterization of a barrier discharge igniter (BDI) and of a corona streamer igniter (CSI) was made at low-speed and two different load conditions on a single-cylinder research engine with gasoline PFI. The aim was to investigate the igniters' behavior at an operating load not yet explored by our research group, by comparing the corresponding results, in terms of indicated analysis and emissions, with the ones obtained at low load in our previous work. In both works, the 
igniter discharge duration was set equal to the maximum allowable values, such as the driving voltage. This latter was fixed for the BDI, whereas the CSI required an optimization in order to avoid arching events. Ignition timing was optimized for each operating point tested and each igniter. The main results of this work are as follows:

- Higher in-cylinder pressure characterized the ML condition. In this case, considering the same $\lambda$ values, reduced IT were used compared to the LL case, for both igniters. CSI needs reduced IT in both load conditions with respect to BDI. At higher load, higher driving voltage can be used, thus obtaining more energetic discharges. Higher IMEP was recorded once operating with wider throttle valve opening. No appreciable differences in terms of IMEP were found between corona igniters at the same load conditions.

- $\quad$ ML led to an extension of the lean stable limit $\left(\lambda_{\mathrm{BDI}}=1.647, \lambda_{\mathrm{CSI}}=1.725\right)$ for both igniters compared to the LL case $\left(\lambda_{\mathrm{BDI}}=1.55, \lambda_{\mathrm{CSI}}=1.60\right)$. While at LL the similar combustion durations performed by the igniters led to a similar lean extension, at ML the CSI was able to perform a higher extension by means of a highly lower combustion duration compared to BDI.

- At both load cases, BDI was featured with slower first combustion part (CA0-50). While at LL, BDI showed off a faster second combustion part (CA50-90), at ML CSI was found to be faster in all the combustion ranges.

- According to the abovementioned combustion speeds, while at LL BDI was characterized by lower CO compared to CSI, at ML its slower combustion led to higher CO emissions. In general, the ML case was characterized by lower $\mathrm{CO}$ values and higher NOx emission for both igniters compared to the low load case. The first one is probably correlated to turbulence motions which enhance the mixing by promoting the fuel oxidation, whereas the second one seems to be caused by the higher operating temperature due to the higher-pressure levels inside the chamber.

In the second part of the work the igniters were tested in the constant-volume vessel in order to give an estimation of the thermal energy released by the device during the engine test. An operating condition as close as possible to the engine one was chosen to develop the test. The high thermal energy of CSI can be one of the reasons which could justify the reduced IT. The advanced IT required by the BDI and its faster combustion after the MF50 could be correlated to the production of longlasting chemical species such as ozone, characterized by long time formation.

Author Contributions: Conceptualization, F.R.; methodology, F.R., V.C. and L.P.; software, F.R.; formal analysis F.R.; validation S.P.; investigation, F.R. and L.P.; resources, G.D.; data curation, F.R. and L.P.; writing-original draft preparation, F.R.; writing-review and editing, V.C. and G.D.; visualization, F.R.; supervision, C.N.G.; project administration, C.N.G. All authors read and agreed to the published version of the manuscript.

Funding: this research activity was partially granted by the Basic Research Funds supplied by the Department of Engineering of the University of Perugia.

Conflicts of Interest: The authors declare no conflict of interest.

\section{Glossary and Nomenclature}

aIT after ignition timing

aTDC after top dead center

ACIS advanced corona ignition system

BDI barrier discharge igniter

CAD crank angle degree

CFD computational fluid dynamics

CoV coefficient of variation

CSI corona-streamer igniter

ECU engine control unit

EGR exhaust gas recirculation

GDI gasoline direct injection

LL low load conditions

IMEP indicated mean effective pressure 


$\begin{array}{ll}\text { IT } & \text { ignition timing } \\ \text { LTP } & \text { low-temperature plasma } \\ \text { MBT } & \text { maximum brake torque } \\ \text { MFB } & \text { mass fraction burned } \\ \text { MON } & \text { motor octane number } \\ \text { Pcyl }_{\text {mean in-cylinder pressure }} & \text { mear fuel injection } \\ \text { PFI } & \text { port } \\ \text { ML } & \text { medium load condition } \\ \text { RLC } & \text { resistor-inductor-capacitor } \\ \text { RON } & \text { research octane number } \\ \text { ToN } & \text { corona duration - activation time } \\ \text { TTL } & \text { transistor-transistor logic } \\ \text { VD } & \text { driving voltage } \\ \lambda & \text { air/fuel ratio } \\ \text { ER } & \text { thermal energy released }\end{array}$

\section{References}

1. Alshammari, M.; Alshammari, F.; Pesyridis, A. Electric Boosting and Energy Recovery Systems for Engine Downsizing. Energies 2019, 12, 4636, doi:10.3390/en12244636.

2. Ravaglioli, V.; Bussi, C. Model-Based Pre-Ignition Diagnostics in a Race Car Application. Energies 2019, 12, 2277, doi:10.3390/en12122277.

3. Zsiga, N.; Voser, C.; Onder, C.; Guzzella, L. Intake Manifold Boosting of Turbocharged Spark-Ignited Engines. Energies 2013, 6, 1746-1763, doi:10.3390/en6031746.

4. Kim, T.; Park, J.; Cho, H. Emission Characteristics under Diesel and Biodiesel Fueled Compression Ignition Engine with Various Injector Holes and EGR Conditions. Energies 2020, 13, 2973, doi:10.3390/en13112973.

5. Hu, B.; Li, J.; Li, S.; Yang, J. A Hybrid End-to-End Control Strategy Combining Dueling Deep Q-network and PID for Transient Boost Control of a Diesel Engine with Variable Geometry Turbocharger and Cooled EGR. Energies 2019, 12, 3739, doi:10.3390/en12193739.

6. Zembi, J.; Battistoni, M.; Ranuzzi, F.; Cavina, N.; De Cesare, M. CFD Analysis of Port Water Injection in a GDI Engine under Incipient Knock Conditions. Energies 2019, 12, 3409, doi:10.3390/en12183409.

7. Jiang, L.J.; Shy, S.S.; Nguyen, M.T.; Huang, S.Y.; Yu, D.W. Spark ignition probability and minimum ignition energy transition of the lean iso-octane/air mixture in premixed turbulent combustion. Combust. Flame 2018, 187, 87-95, doi:10.1016/j.combustflame.2017.09.006.

8. Zembi, J.; Mariani, F.; Battistoni, M. Large Eddy Simulation of Ignition and Combustion Stability in a Lean SI Optical Access Engine. SAE Tech. Pap. 2019, doi:10.4271/2019-24-0087.

9. Wang, J.; Yan, F.; Fang, N.; Yan, D.; Zhang, G.; Wang, Y.; Yang, W. An Experimental Investigation of the Impact of Washcoat Composition on Gasoline Particulate Filter (GPF) Performance. Energies 2020, 13, 693, doi:10.3390/en13030693.

10. Aleiferis, P.G.; Taylor, A.M.K.P.; Ishii, K.; Urata, Y. The Nature of Early Flame Development in a Lean-Burn Stratified-Charge Spark-Ignition Engine. Combust. Flame 2004, 136, 283-302, doi:10.1016/j.combustflame.2003.08.011.

11. Mao, B.; Chen, P.; Liu, H.; Zheng, Z.; Yao, M. “Gasoline compression ignition operation on a multi-cylinder heavy duty diesel engine. Fuel 2018, 215, 339-351, doi:10.1016/j.fuel.2017.09.020.

12. Heywood, J.B. Internal Combustion Engine Fundamentals; McGraw-Hill: New York, NY, USA. 1988; ISBN 007-028637-X.

13. Wu, Y.-Y.; Wang, J.H.; Mir, F.M. Improving the Thermal Efficiency of the Homogeneous Charge Compression Ignition Engine by Using Various Combustion Patterns. Energies 2018, 11, 3002, doi:10.3390/en11113002.

14. Mofijur, M.; Hasan, M.; Mahlia, T.; Rahman, S.A.; Silitonga, A.; Ong, H.C. Performance and Emission Parameters of Homogeneous Charge Compression Ignition (HCCI) Engine: A Review. Energies 2019, 12, 3557, doi:10.3390/en12183557.

15. Meng, L.; Luo, J.; Yang, X.; Zeng, C. Intake Air Mass Observer Design Based on Extended Kalman Filter for Air-Fuel Ratio Control on SI Engine. Energies 2019, 12, 3444, doi:10.3390/en13051148. 
16. Alger, T.; Gingrich, J.; Roberts, C.; Mangold, B. A High Energy Continuous Discharge Ignition System for Dilute Engine Applications. SAE Tech. Pap. 2013, doi:10.4271/2013-01-1628.

17. Poggiani, C.; Cimarello, A.; Battistoni, M.; Grimaldi, C. Optical Investigations on a Multiple Spark Ignition System for Lean Engine Operation. SAE Tech. Pap. 2016, doi:10.4271/2016-01-0711.

18. Dale, J.D.; Checkel, M.D.; Smy, P.R. Application of High Energy Ignition Systems to Engines. Prog. Energy Combust. Sci. 1997, 23, 379-398, doi:10.1016/S0360-1285(97)00011-7.

19. Badawy, T.; Bao, X.; Xu, H. Impact of spark plug gap on flame kernel propagation and engine performance. Appl. Energy 2017, 191, 311-27, doi:10.1016/j.apenergy.2017.01.059.

20. Breden, D.; Karpatne, A.; Suzuki, K.; Raja, L. High-fidelity numerical modeling of spark plug erosion. $S A E$ Tech. Pap. 2019, 2019-April, 1-12, doi:10.4271/2019-01-0215.

21. Lasagni, A.; Soldera, F.; Mücklich, F. FEM simulation of local heating and melting during electrical discharge plasma impact. Model. Simul. Mater. Sci. Eng. 2004, 12, 835-844, doi:10.1088/0965-0393/12/5/005.

22. Shiraishi, T.; Urushihara, T. Fundamental Analysis of Combustion Initiation Characteristics of Low Temperature Plasma Ignition for Internal Combustion Gasoline Engine. SAE Tech. Pap. 2011, 399-408, doi:10.4271/2011-01-0660.

23. Starikovskaia, S.M. Plasma assisted ignition and combustion. J. Phys. D Appl. Phys. 2006, 39, R265-R299.

24. Defilippo, A.C.; Saxena, S.; Rapp, V.; Dibble, R.W.; Chen, J.-Y.; Nishiyama, A.; Ikeda, Y. Extending the Lean Stability Limits of Gasoline Using a Microwave-Assisted Spark Plug. SAE Tech. Pap. 2011, doi:10.4271/201101-0663.

25. Starikovskii, A.Y.; Anikin, N.B.; Kosarev, I.N.; Mintoussov, E.I. Nanosecond Pulsed Discharges for Plasma Assisted Combustion and Aerodynamics. J. Propuls. Power 2008, 24, 1182-1197, doi:10.2514/1.24576.

26. Pineda, D.I.; Wolk, B.; Chen, J.-Y.; Dibble, R.W. Application of Corona Discharge Ignition in a Boosted Direct-Injection Single Cylinder Gasoline Engine: Effects on Combustion Phasing, Fuel Consumption, and Emissions. SAE Int. J. Engines 2016, 9, 1970-1988, doi:10.4271/2016-019045.

27. Subramaniam, V.; Karpatne, A.; Breden, D.; Raja, L. Simulation of Spark-Initiated Combustion. SAE Tech. Pap. 2019, doi:10.4271/2019-01-0226.

28. Ju, Y.; Sun, W. Plasma assisted combustion: Dynamics and chemistry. Prog. Energy Combust. Sci. 2015, 48, 21-83, doi:10.1016/j.pecs.2014.12.002.

29. Starikovskaia, S.M. Plasma-assisted ignition and combustion: Nanosecond discharges and development of kinetic mechanisms. J. Phys. D Appl. Phys. 2014, 47, 353001.

30. Popov, N.A. Kinetic processes initiated by a nanosecond high-current discharge in hot air. Plasma Phys. Rep. 2011, 37, 807-815, doi:10.1134/S1063780X1108006X.

31. Rickard, M.; Dunn-Rankin, D.; Weinberg, F.; Carleton, F. “Characterization of Ionic Wind Velocity. J. Electrost. 2005, 63, 711-716, doi:10.1016/j.elstat.2005.03.033.

32. Burrows, J.; Mixell, K. New Developments and Optimization of the Advanced Corona Ignition System (ACIS). In Proceedings of the 4th International Conference on Ignition Systems for Gasoline Engines, Berlin, Germany, 6-7 December 2018; pp. 340-370.

33. Idicheria, C.A.; Najt, P.M. "Potential of Advanced Corona Ignition System (ACIS) for Future Engine Applications. In Ignition Systems for Gasoline Engines. CISGE 2016; Günther, M., Sens, M., Eds.; Springer: Cham, Switzerland, 2017.

34. Discepoli, G.; Cruccolini, V.; Ricci, F.; di Giuseppe, A.; Papi, S.; Grimaldi, C.N. Experimental characterisation of the thermal energy released by a Radio-Frequency Corona Igniter in nitrogen and air. Appl. Energy 2020, 263, 114617, doi:10.1016/j.apenergy.2020.114617.

35. Cruccolini, V.; Discepoli, G.; Cimarello, A.; Battistoni, M.; Mariani, F.; Grimaldi, C.N.; Re, M.D. Lean combustion analysis using a corona discharge igniter in an optical engine fueled with methane and a hydrogen-methane blend. Fuel 2020, 259, 116290, doi:10.1016/j.fuel.2019.116290.

36. Breden, D.P.; Idicheria, C.A.; Keum, S.; Najt, P.M.; Raja, L.L. Modeling of a Dielectric-Barrier DischargeBased Cold Plasma Combustion Ignition System. IEEE Trans. Plasma Sci. 2019, 47, 410-418, doi:10.1109/TPS.2018.2882830.

37. Biswas, S.; Ekoto, I.; Scarcelli, R. Alternative Ignition Systems Applications. In Proceedings of the 4th International Conference on Ignition Systems for Gasoline Engines, Berlin, Germany, 6-7 December 2018; pp. 311-328. 
38. Burrows, J.; Mixell, K. Analytical and Experimental Optimization of the Advanced Corona Ignition System. In Ignition Systems for Gasoline Engines; Springer International Publishing: Cham, Switzerland, 2016; pp. 267-292, doi:10.1007/978-3-319-45504-4_17.

39. Marko, F.; König, G.; Schöffler, T.; Bohne, S.; Dinkelacker, F. Comparative Optical and Thermodynamic Investigations of High Frequency Corona- and Spark- Ignition on a CV Natural Gas Research Engine Operated with Charge Dilution by Exhaust Gas Recirculation. In Ignition Systems for Gasoline Engines; Springer International Publishing: Cham, Switzerland, 2017; pp. 293-314, ISBN 978-3-319-45503-7, doi:10.1007/978-3-319-45504-4_18.

40. Yu, S.; Wang, M.; Zheng, M. Distributed Electrical Discharge to Improve the Ignition of Premixed Quiescent and Turbulent Mixtures; SAE Technical Paper 2016-01-0706; SAE: Warrendale, PA, USA, 2016; doi:10.4271/201601-0706.

41. Cimarello, A.; Grimaldi, C.; Mariani, F.; Battistoni, M.; Re, M.D. Analysis of RF Corona Ignition in Lean Operating Conditions Using an Optical Access Engine. SAE Tech. Pap. 2017, doi:10.4271/2017-01-0673.

42. Lo, A.; Cessou, A.; Lacour, C.; Lecordier, B.; Boubert, P.; A Xu, D.; O Laux, C.; Vervisch, P. Streamer-toSpark Transition Initiated by a Nanosecond Overvoltage Pulsed Discharge in Air. Plasma Sources Sci. Technol. 2017, 26, 045012, doi:10.1088/1361-6595/aa5c78.

43. Zhang, A.; Scarcelli, R.; Wallner, T.; Breden, D.P.; Karpatne, A.; Raja, L.L.; Ekoto, I.; Wolk., B. Numerical Investigation of Nanosecond Pulsed Discharge in Air at above Atmospheric Pressures. J. Phys. D Appl. Phys. 2018, 51, 345201, doi:10.1088/1361-6463/aad262.

44. Cimarello, A.; Cruccolini, V.; Discepoli, G.; Battistoni, M.; Mariani, F.; Grimaldi, C.; Re, M.D. Combustion Behavior of an RF Corona Ignition System with Different Control Strategies. SAE Tech. Pap. 2018, doi:10.4271/2018-01-1132.

45. Discepoli, G.; Cruccolini, V.; Re, M.D.; Zembi, J.; Battistoni, M.; Mariani, F.; Grimaldi, C. Experimental Assessment of Spark and Corona Igniters Energy Release. Energy Procedia 2018, 148, 1262-1269, doi:10.1016/j.egypro.2018.08.001.

46. Idicheria, C.A.; Yun, H.; Najt, P.M. An Advanced Ignition System for High Efficiency Engines. In Proceedings of the 4th International Conference on Ignition Systems for Gasoline Engines, Berlin, Germany, 6-7 December 2018; pp. 40-54, doi:10.5445/IR/1000088317.

47. Shcherbanev, S.; De Martino, A.; Khomenko, A.; Starikovskaia, S.; Padala, S.; Ikeda, Y. Emission Spectroscopy Study of the Microwave Discharge Igniter. SAE Tech. Pap. 2017, doi:10.4271/2017-24-0153.

48. Enloe, C.L.; Mangina, R.S.; Font, G.I. Normalized electronegative species effects in the dielectric-barrierdischarge plasma actuator. AIAA J. 2016, 54, 2061-8, doi:10.2514/1.J054551.

49. Burrows, J.; Mixell, K.; Reinicke, P.B.; Riess, M.; Sens, M. Corona Ignition-Assessment of Physical Effects by Pressure Chamber, Rapid Compression Machine, and Single Cylinder Engine Testing. In Proceedings of the 2nd International Conference on Ignition Systems for Gasoline Engines, Berlin, Germany, 24-25 November 2014.

50. Yun, H.; Idicheria, C.; Najt, P. The Effect of Advanced Ignition System on Gasoline Low Temperature Combustion. Int. J. Engine Res. 2019, doi:10.1177/1468087419867543.

51. Bresler, M.; Attard, W.; Reese, R. Investigation of Alternative Ignition System Impact on External EGR Dilution Tolerance in a Turbocharged Homogeneous Direct Injected Spark Ignited Engine. SAE Int. J. Engines 2015, 8, 1967-1976, doi:10.4271/2015-01-9043.

52. Irimescu, A.; Tornatore, C.; Marchitto, L.; Merola, S.S. Compression Ratio and Blow-by Rates Estimation Based on Motored Pressure Trace Analysis for an Optical Spark Ignition Engine. Appl. Therm. Eng. 2013, 61, 101-109, doi:10.1016/j.applthermaleng.2013.07.036.

53. Irimescu, A.; Merola, S.S.; Tornatore, C.; Valentino, G.; Grimaldi, A.; Carugati, E.; Silva, S. Plasma Assisted Ignition Effects on a DISI Engine Fueled with Gasoline and Butanol under Lean Conditions and with EGR. SAE Tech. Pap. 2016, doi:10.4271/2016-01-0710.

54. Merola, S.S.; Irimescu, A.; Valentino, G.; Tornatore, C.; Silva, S.; Grimaldi, A.; Carugati, E. Experimental Evaluation of an Advanced Ignition System for GDI Engines. SAE Int. J. Engines 2015, 8, 2351-2367.

55. Ricci, F.; Zembi, J.; Battistoni, M.; Grimaldi, C.; Discepoli, G. Experimental and Numerical Investigations of the Early Flame Development Produced by a Corona Igniter. SAE Tech. Pap. 2019, doi:10.4271/2019-240231 . 
56. Cruccolini, V.; Discepoli, G.; Ricci, F.; Petrucci, L.; Grimaldi, C.; Papi, S.; Re, M.D. Comparative Analysis between a Barrier Discharge Igniter and a Streamer-type Radio-Frequency Corona Igniter in an Optically Accessible Engine in Lean Operating Conditions. SAE Tech. Pap. 2020, doi:10.4271/2020-01-0276.

57. Hahn, J.; Schenk, M.; Schauer, F.X.; Sauer, C.; Weber, G.; Schwarz, C. From glow tube to coronaChallenges to the ignition systems of future SI engines. In Internationaler Motorenkongress 2017. Proceedings; Liebl, J., Beidl, C., Eds.; Springer Vieweg: Wiesbaden, Germany, doi:10.1007/978-3-658-17109-4_9.

58. Hwang, J.; Kim, W.; Bae, C.; Choe, W.; Cha, J.; Woo, S. Application of a novel microwave-assisted plasma ignition system in a direct injection gasoline engine. Appl. Energy 2017, 205, 562-576, doi:10.1016/j.apenergy.2017.07.129.

59. Singleton, D.; Pendleton, S.J.; Gundersen, M.A. The role of non thermal transient plasma for enhanced flame ignition in C2H4 air. J. Phys. D Appl. Phys. 2010, 44, 022001, doi:10.1088/0022-3727/44/2/022001.

60. Scarcelli, R.; Wallner, T.; Som, S.; Biswas, S.; Ekoto, I.; Breden, D.P.; Karpatne, A.; Raja, L.L. Modeling Non-Equilibrium Discharge and Validating Transient Plasma Characteristics at above Atmospheric Pressure. Plasma Sources Sci. Technol. 2018, 27, 124006, doi:10.1088/1361-6595/aaf539.

61. Bikas, G.; Michos, K. Carbon Monoxide Emissions Model for Data Analytics in Internal Combustion Engine Applications Derived from Post-Flame Chemical Kinetics. SAE Int. J. Engines 2018, 11, 947-964, doi:10.4271/2018-01-1153.

62. Nebel, G.J.; Jackson, M.W. Some Factors Affecting the Concentration of Oxides of Nitrogen in Exhaust Gases from Spark Ignition Engines. J. Air Pollut. Control Assoc. 1958, 8, 213-219, doi:10.1080/00966665.1958.10467847.

63. Eliasson, B.; Kogelschatz, U. Nonequilibrium volume plasma chemical processing. IEEE Trans. Plasma Sci. 1991, 19, 1063-1077, doi:10.1109/27.125031.

64. Wang, Z.H.; Yang, L.; Li, B.; Li, Z.S.; Sun, Z.W.; Aldén, M.; Cen, K.F.; Konnov, A.A. Investigation of combustion enhancement by ozone additive in $\mathrm{CH}_{4} /$ air flames using direct laminar burning velocity measurements and kinetic simulations. Combust. Flame 2012, 159, 120-129, doi:10.1016/j.combustflame.2011.06.017.

65. Eliasson, B.; Hirth, M.; Kogelschatz, U. Ozone synthesis from oxygen in dielectric barrier discharges. J. Phys. D Appl. Phys. 1987, 20, 1421-1437. 